\title{
Does QFII Uphold Value Investment? Evidence from China
}

\author{
Li Qiang ${ }^{1,2, *}$, Dong Yaowu ${ }^{3}$, Jin Zhenhu ${ }^{4}$ \\ ${ }^{1}$ College of Big Data Applications and Economics, Guizhou University of Finance and Economics, Huaxi \\ University City, Guiyang, China \\ ${ }^{2}$ Guizhou Province Big Data Statistical Analysis Key Laboratory, Huaxi University City, Guiyang, China \\ ${ }^{3}$ School of Finance, Guizhou Business School Finance College, Baiyun District 26 Street, Guiyang, China \\ ${ }^{4}$ School of Business, Valparaiso University, 215 Urschel Hall, Valparaiso, USA
}

Keywords: Copulas function; Tail dependence structure; Value investment; Value at Risk; QFII stock Index

\begin{abstract}
The Basic Law and investment idea of value investment is widely used in developed Western financial market, but it still needs to be verified in the emerging and transition China. In this paper, the QFII investment strategy is feasible in China, that is, the ASV-GPD model is the marginal distribution function, and the correlation between QFII and HS300 index is studied by using four kinds of copula cluster methods. It is concerned with the statistical modeling of the dependence structure of QFII and HS300 index using the theory of Copulas. We select four Copulas and identify the type of dependency to capture nonlinear asymmetric and tail dependence. The GPD model needs to estimate the threshold values in order to exactly fit the margin distribution of Copula functions. Our analysis is based on a semi-parametric extreme value model. EV Copulas, Archimax Copulas and Archimedean Copulas simulate the correlation between QFII index and HS300 index. The empirical analysis indicates that the BB1 Copula has a higher correlation in the lower tail than the upper tail for a variety of parameters used in the Copula function. These findings illustrate that two different return series are more likely to correlate with each other during market downturns than upturns. Moreover, the backtesting results show that Copula-ASV-GPD model is suitable for measurement of tail risk of QFII and HS300 portfolio. In addition, we find the striking evidence of QFII value investment in Chinese A-share stock market for the period 2006-2018. Meanwhile QFII institutional investors gradually increase and the improvement of listed companies' profit sharing system so that there is an opportunity for the rational return of value investment in Chinese stock markets.
\end{abstract}

\section{Introduction}

With the deepening of economic globalization and financial internationalization, as well as the deepening of the external opening of China's financial markets, internationalization has become the trend of irreversible development of financial markets in China. At the same time, the uncertainty of internationalization investment strategy and in come makes the study of fluctuation correlation more and more important. At 2002 began to implement the QFII system in China in the month of the year. The original intention of introducing QFII system is to advocate the value investment decision based on the fundamentals of stock. QFII is basically a rational institutional investor with a long-term investment philosophy, adhere to the principle of sound investment, has a wealth of operating experience and good performance, good at analyzing the company's fundamental information, preferring to hold good prospects for high-performance blue chips. Shanghai and Shenzhen Large- cap blue-chip stocks (HS300). Because of its excellent performance, stable development, large scale of equity, good liquidity and other characteristics, can be used as a model for value investment. However, as China's capital market is not yet perfect, the speculative idea of trend investment has long dominated the market change, such as the low overall quality and the lack of reasonable dividend system. China's economic development has entered a new normal in recent years, the pain of economic transformation and structural adjustment. And the new growth model is 
still exploring, HS300 shows the extremely rare investment value, particularly in 2008 and 2015.The world financial crisis and the huge adjustment period of China's capital market. The academic and practical circles need to rethink and examine the applicability of value investment in China's securities market, so QFII's investment strategy has naturally aroused people's concern: QFII is it to achieve a return on investment to constantly adjust its investment strategy, and ultimately no longer adhere to its value investment style? Or always uphold the value of the investment strategy? Or because of its limited size, it is difficult to steer the market in a healthy direction through its investment philosophy? What new characteristics and investment ideas will be displayed in the new normal economic environment as a result of the state bail-out caused by the wide-2015 of China's securities market in two years? In response to these questions, we try to pass the QFII shareholding index with the HS300 index. The correlation of fluctuation is studied in the hope that we can understand the value investment from a brand-new perspective and try to explore. Some of the more essential things that have been ignored by the academic and practical community market place characteristics.

For reference to Taiwan and South Korea QFII system, the first QFII from 2003 introduced. Since the mainland China market, some scholars have generally experienced the following stages in the study of value investment: (1) Groping Stage. Is value investment applicable to the Chinese stock market? For example, He Xiannan (2003) thinks securities investment fund to advocate value investment encounter dilemma as a case [1], that value investment in China still lacks a solid foundation, The value investment model advocated by the fund's concentrated shareholding has alienation as the risk of market hype; (2) Empirical Stage. The empirical research of value investment and the use of behavioral finance to explain (such as Shao xiaoyang; Wang Jin bin; Chen Yaonen, etc [2-5]; (3) Expansion phase. The expansion research in the field of value investment has the Chen Xiaohong, Song jun and so on [6,7]; (4) Silent stage. Post-world financial crisis and 2015-2016 years China stock market exceptions volatility after that, Mainstream journals have little value Investment research literature publish.

Although the above research has made a beneficial exploration for the applicability of value investment in China's securities market, none of the above studies have been able to reveal the mechanism of the difference in the tail performance of the current large-cap blue-chip valuation during the crisis. In the past, domestic scholars' research on value investment theory mainly focused on empirical research, such as the use of improved intrinsic value model, premium rate four factor model, value orientation model, book-market price ratio effect and so on. Despite the US subprime mortgage crisis and the European sovereign debt crisis, the correlation of financial assets has once again become the focus of research, but for QFII shareholding index and Shanghai and Shenzhen.

The studies on the correlation of indices are rare, But also fresh. There is a literature to measure the associated risks of asymmetric and tail extremum between two indices. In summary, considering that the related structure of financial asset income is usually nonlinear, the marginal risk presents thick tail and asymmetric characteristics, while the copula function can by portraying volatility continuity and addressing thick tail and asymmetric properties to fully describe the dependent structure. This paper provides a new research perspective, using Copula function to quantitatively study QFII shareholding index and HS300 correlation between the index.

Copula function is a powerful tool to construct multivariate joint distribution and correlation structure analysis between random variables, and the correlation measure derived from Copula not only can describe the complex nonlinear and asymmetric correlations between variables, but also can be well describe the tail correlation of the distribution. Tail correlation analysis is often used to describe the degree of asymmetry between financial markets when extreme situations occur, and the Extremum model (EVT) is the most effective method to study tail distribution at present, combining EVT and Copula theory is a development trend depicting the multivariate joint distribution of financial markets. Di Clemente and Romano believe that the Copula-EVT method can be better fitted than the normal distribution and accurate estimation of financial data [8]. Based on the four Morgan Stanley U.S. stock indices during the 1992.6-2006.6 period, Viviana Fernandez chose the best Copula function depicts the synergy between 22 sequences, and the results show that t-Copula 
is better portrayed [9]. Madhusudan Karmakar and other applications a CGARCH-EVT-Copula and other the model conducts risk measurement studies on three market indices, including India, the United Kingdom and the US, and the return test shows that CGARCH-EVT-Copula class models are superior to other models [10,11].

Li Jun combined Copula and EVT theory to construct the tail dependent structure of financial data, and thought that Gumbel Copula [12]. It can fit the tail dependent structure of Shanghai and Shenzhen stock index well. Fu qiang and Xing linlin carried out an empirical study of deep index through Gumbel Copula based on conditional VaR [13]. Li yulei and other uses Copula and EVT theory to study the manipulation prevention of Shanghai and Shenzhen index futures, and the corresponding prevention strategy is given [14]. Liu qiongfang and Zhang Zongyi adopted the correlation structure between the stock yield of Copula fitting real estate and financial industry, and found that the Copula of double parameter structure was studied. The fitting fit is generally higher than that of the single-parameter structure of Copula [15]. Copula-ASV-EVT-CoVaR for Zhou xiaohua and other operations the model studies the risk spillover effect of small and gem in China [16-18].

The frequent financial crisis and the violent fluctuation of financial markets make risk management a subject of great concern, in terms of risk value (VaR) with its concise economic meaning, comprehensive measurement of risk and ease of operation, widely used in the field of risk management and financial supervision. The key to accurately predicting VaR lies in the distribution setting of financial asset return error and the prediction of volatility. In terms of the distribution setting of the return error of financial assets, $\mathrm{VaR}$, based on the normal assumption, is easy to underestimate the tail risk because it ignores the extreme events because it neglects the real financial asset yield distribution thick tail and asymmetric characteristics. The defect of VaR is that it is discontinuous and does not satisfy the secondary additive, and the existence is neither micronor convex. And CVaR as a supplementary model can make up for the above defects.

In the forecast of financial asset fluctuation, asymmetric random fluctuation (asymmetry stochastic volatility, ASV) combines the dual roots of mathematical finance and financial econometrics, with two noise processes that have an advantage over only one error item in the GARCH model, Because it can accurately describe the financial timing, it is considered to be an ideal model to depict the asymmetric volatility of financial markets. Wu xinyu believes that the SV model has better sample fitting and out-of-sample prediction capabilities than the GARCH model, and the model is more flexible [19]. Liu zhidong based on the hybrid genetic algorithm of simplex and traditional genetic algorithm, GARCH- EVT reflects the tail distribution and volatility of the yield of China's securities market, and constructs a Copula the asset portfolio selection model of the function and carries out the risk measurement [20]. Zhan xueli and Zhang shiying established the normal copula-SV model and compared it with the Copula-GARCH model, and the results show that the Copula-SV model has superiority over the Copula-GARCH model in characterizing the $\mathrm{VaR}$ value of combinatorial risk [21]. Li pengju and Zhu hui based on t-GARCH-Copula model to depict the peak and thick tail characteristics of the actual distribution of financial management product income, The Monte Carlo simulation was used to analyze the risk of the investment portfolio in the pre-financial crisis period [22].

However, most of the above studies are based on the assumption that the income distribution obeys the normal distribution, using the standard GARCH or SV. It is difficult for the model to accurately depict the asymmetry of financial asset income and the characteristics of peak thick tail, and there are some limitations. Therefore, exploring the extended ASV model reflects asymmetric volatility, and combines the GPD model to describe the peak and thick tail characteristics of financial asset returns. A comprehensive description of the thick tail and asymmetric characteristics of financial asset returns is carried out, and the standardized residuals of the ASV-GPD model are fitted and tested, taking into account the VaR. As a common and benchmark method for financial market and portfolio risk, It is also necessary to pay attention to the problems of lower end extremum, asymmetric dependencies between data and estimation error items, combined with more than expected loss CVaR together with the measure as a supplement. 
The difference between this pape Karmakar $\mathrm{M}$ and other studies is that the first is not selected GARCH Class model, but consider the ASV model with more asymmetric advantages , and second , there is no subjective choice Copula function to fit the dependent structure, But to fit all the four commonly used categories. Copula models elective optimal Copula; Finally different research perspectives, no targeting of the for exchange market a comparative study with multinational stock markets, Instead, it explores whether QFII always invests in China based on value investment strategies. Despite the above differences, but in line with Karmakar M and other studies, this paper shows that the two-parameter BB1 Copula is also the best copula based on the principles of AIC and BIC. The difference between this paper and Zhou Xiaohua and other research is mainly in the research perspective and purpose different, not for China's foreign exchange reserve currency portfolio and China's small and gem risk overflow research, But focuses on the dependent structure to judge the value investment strategy. Unlike Li Qiang and other studies, it is not only to update the sample data, but also for 2008 and 2015 years. The huge fluctuation of China's securities market, the value investment basis of QFII Copula's dependence analysis. Trying to summarize the new characteristics and trends of the volatility of the volatility of the Securities market after the Chinese government's rescued the market. In view of the relatively limited existing theories and research results in this field, this paper attempts to construct the optimal combination model to obtain some useful research conclusions on the fitting ability of China's capital market value investment.

The main contribution of this study is that, on the basis of the existing literature and the research of Li Qiang and so on, the first few literatures empirical study of QFII value investment strategy, this paper selects QFII shareholding index and HS300 index of the daily data is the research object, the application category four Copula clusters Method, and then use the ASV-GPD the model is an edge distribution function, With a qualitative excess mean (MEF) is combined with a quantitative peak method to determine the threshold value, The accuracy of the research conclusion is enhanced, Then expand and compare the new characteristics of the two major fluctuations in Chinese securities. Finally, the correlation between QFII and HS300 two index was studied. Relationship is of great significance, which not only helps to understand the mechanism of value investment, but also provides reference for the formulation of policy decision-making in related departments, as well as helps investors to establish correct investment ideas and optimize investment strategies.

This article and the following structure are as follows: The second part describes methodology. The third part gives the empirical and test results. The last part is the conclusion.

\section{Methodology}

\subsection{ASV-GPD model for the determination of edge distribution thresholds}

Describing the volatility of financial assets is one of the core of risk measurement, the ASV model, by relaxing the hypothesis that the error is not related to each other, highlights the nonsymmetry, and thus closer to financial reality. It manifests itself in the following forms (Li Pengju, etc. It is considered that there are two asymmetric phenomena in the distribution of yield of financial assets: one means that the yield bias of a single asset is not equal to zero, and the second refers to the asymmetry of the correlation between yields. This paper mainly studies the latter asymmetric phenomenon) [22]:

$$
\begin{gathered}
\left\{\begin{array}{l}
X_{t}=\varepsilon_{t} \exp \left(h_{t} / 2\right) \\
h_{t}=\mu+\phi\left(h_{t-1}-\mu\right)+\tau \eta_{t}
\end{array}\right. \\
{\left[\begin{array}{c}
\varepsilon_{t} \\
\eta_{t-1}
\end{array}\right] \sim \text { i.i.d.N }\left(\left(\begin{array}{l}
0 \\
0
\end{array}\right),\left(\begin{array}{cc}
1 & \rho \sigma \\
\rho \sigma & \sigma^{2}
\end{array}\right)\right)}
\end{gathered}
$$

Among them, ${ }^{\varepsilon_{t}}$ and for the wave disturbance of the item $\eta_{t}, \rho \neq 0 \varepsilon_{t}$ and $\boldsymbol{\eta}_{t}$ the asymmetric correlation coefficient, used to indicate ${ }^{\phi}$ the persistence parameters of logarithmic fluctuation reflect the influence of current fluctuation on future fluctuation, and for $|\phi|_{<1 \text {, the ASV model is }}$ 
stable. Represents the logarithmic fluctuation of the day, which is the standard deviation of the normal $h_{t} t \sigma_{\text {state, and is }}{ }^{\tau}$ used to measure the standard error of the fluctuation disturbance.

The parameters to be evaluated in the ASV model are as $\mu, \phi, \tau, \rho$ follows, using the MCMC method of Gibbs sampling, with the help of winbugs software to achieve the ASV parameter estimation, while referring to the Kim and Meyer the experience [23]. The parameters to be evaluated priori distribution set to:

$$
\mu \sim \text { i.i.N(0,100), } \frac{1+\phi}{2} \sim \operatorname{Beta}(20,1.5), \tau^{2} \sim \operatorname{IGamma}(2.5,0.025), v \sim \chi^{2}
$$

Based on the estimation of the parameters of the ASV Model by MCMC method, the gradual independent and distributed random perturbation items $Z_{t}$ are obtained by the corresponding transformation of the income sequence. To achieve the tail modeling condition of]the Hyperthreshold model (POT)[24] .Assuming that $\hat{\mu}_{t}, \hat{\sigma}_{t}$ is the conditional mean and conditional variance of the income sequences, which are based on QFII and HS300, respectively, the most recent $n$ random disturbance term $Z_{t}$ is:

$$
\left(Z_{t-n+1, \cdots, Z_{t}}\right)=\left(\frac{\left.X_{t-n+1}-\hat{\mu}_{t-n+1}, \cdots, \frac{X_{t}-\hat{\mu}_{t}}{\hat{\sigma}_{t}}\right)}{\hat{\sigma}_{t-n+1}}\right.
$$

The financial income sequence has many thick tail, asymmetric and tail extremum correlation, and the advantage of extremum theory is that it does not consider the distribution of the whole yield but focuses only on the progressive value distribution of the hyper-threshold value. Therefore, considering the comparison of the actual and normal distribution of financial data, the generalized Pareto distribution (GPD) is used to estimate the parameters of the super threshold of $Z_{t}$ random variables, The Gaussian kernel smoothing method (cumulative distribution function of experience, $\mathrm{CDF}$ ) is used to estimate the middle part of edge distribution in based on the advantages of parameter estimation and non-parametric estimation, a semi-parametric model is obtained:

$$
\mathrm{F}(\mathrm{Z})=\left\{\begin{array}{l}
\frac{N_{u}^{L}}{N}\left(1+\xi^{L} \frac{u^{L}-z}{\beta^{L}}\right)^{-1 / \xi^{L}}, \quad z<u^{L} \\
C D F \quad \Phi(z), u^{L} \leq z \leq u^{R} \\
1-\frac{N_{u}^{R}}{N}\left(1+\xi^{R} \frac{z-u^{R}}{\beta^{R}}\right)^{-1 / \xi^{R}}, z>u^{R}
\end{array}\right.
$$

Wherein, $u^{R}$ and respectively, are represented $u^{L}$ as the upper and lower end thresholds for random perturbation items, correspondingly, $\xi^{R}$ and $\xi^{L}$ for the upper and lower end of the shape parameters, $\beta^{R}$ and $\beta^{L}$ for the upper and lower end of the scale parameters. The number of samples in $N_{u}^{L}$ below the lower end threshold, the number of samples in $N_{u}^{R}$ higher than the upper tail threshold, and the number of samples of the random disturbance item.

GPD is essentially an observation of the amount of data order of the hyper-threshold, so it is important to choose a reasonable threshold. If the threshold value is too high, although it satisfies $U$ the characteristics of GPD distribution, but because too little limit value is easy to make the parameter estimation produce a large variance, if the elective threshold ${ }^{U}$ is too low, it is difficult to ensure the convergence of the super threshold distribution, easy to produce biased estimation. McNeil and Frey proposed a method for the intersection of thick tail distribution and normal distribution to determine the threshold value [25], Although this method has theoretical advantages compared with the qualitative methods commonly used in practice, such as excess limit and Hill graph method, it is necessary to clarify the specific distribution form in practical solution, and the distribution parameters are generally unknown, so the solution process is very complicated. According to the limitation of its existence, Pieere Patie proposed peak method according to the 
peak coefficient value of sample order quantity[26], its working principle and thick tail distribution and normal distribution intersecting method similar, from a quantitative point of view to determine the threshold value, easier to understand and easy to operate. Its operating steps can be summed up as:

First step: Calculate sample mean and sample peak $\bar{X} K_{n}$

$$
\begin{array}{r}
\bar{X}_{n}=\frac{X_{1}+X_{2}+\cdots+X_{n}}{n} \\
K_{n}=\frac{E\left(X_{i}-\bar{X}_{n}\right)^{4}}{\left[E\left(X_{i}-\bar{X}_{n}\right)^{2}\right]^{2}}, i=1,2, \cdots, n
\end{array}
$$

The second step: to judge the peak, if so, choose to make the value of the largest, remove it from the sample. If $K_{n} \geq 3$, So we select the maximum value $X_{i}$ from $\left|X_{i}-\bar{X}_{n}\right|$.

The third step: Repeat first to second step until the peak is less than 3.

The fourth step: Select the largest ${ }^{X_{i}}$ of the remaining sample points and select this value as the threshold.

In order to make the threshold selection more reasonable, both methods of qualitative mean excess function (MEF) and quantitative peak method are used to determine the threshold of edge distribution.

\subsection{Selection of copula functions}

The basic Problem of applying Copula function is to choose the best Copula function to depict the dependent structure between financial markets. First of all, we need to solve two problems: one is the choice of the Copula function form, the Copula function commonly used in the current financial correlation analysis mainly has the ellipse Copula Function clusters, Archimedes Copula Function clusters, extremum Copula Function Clusters and Archimax Copula Function clusters, etc. The second is Copula estimation of parameters, in the use of the maximum likelihood method (MLE) and the edge distribution derivation method (IFM) estimating multiple Copula. When the parameters of the function are Copula the accuracy of function parameter estimation depends strongly on the fitting of the edge distribution of a single financial market, that is, the higher the fitting fit of the edge distribution, Copula the more accurate the parameter estimation of a function, the closer the dependent structure between financial assets is to the real structure. The fitting test of copula model includes the test of edge distribution model and the fitting optimization test of copula function.

Modeling the correlation structure between financial markets, The advantage of the Copula function is that the joint distribution function can be decomposed into two parts, the edge distribution function and the Copula function, which describe the information of each financial market. From the Sklar theorem: order $F_{X Y}$ it's the edge distribution. $F_{X}$ and $F_{Y}$ of two Yuan the federated distribution function.

For all $(x, y) \in[-\infty, \infty]$, there is Copula Function $C(\because$,$) Meet:$

$$
F_{X Y}(x, y)=C\left(F_{X}(x), F_{Y}(y)\right)
$$

Order $u=F_{X}(x), v=F_{Y}(y)$, if $F_{X}$ and $F_{Y}$ is continuous, $C(u, v)$ is unique.

Next, the maximum likelihood estimation program is introduced, which is realized by substantially the pseudo-likelihood value of all pairs of variables.

Assuming $(k, l) \in\{1, \ldots, d\}^{2}$ that all, is the Copula associated with the $C_{k l}$ random pair $\left(U_{k}, U_{l}\right)$, if given

$$
C_{k l}\left(u_{k}, u_{l}\right)=C\left(1, \ldots, 1, u_{k}, 1, \ldots, 1, u_{l}, 1, \ldots, 1\right)
$$




$$
\arg \max _{\theta} \sum_{m=1}^{n} \sum_{k l} \log c_{k l}\left(\widehat{F}_{k}\left(x_{k}^{(m)}\right), \hat{F}_{l}\left(x_{l}^{(m)}\right) ; \theta_{k l}\right)
$$

In the formula is the double variable density associated with it $c_{k l} C_{k l}$, given the following

$$
F_{X Y}(x, y)=C\left(F_{X}(x), F_{Y}(y)\right)
$$

Then consider the use of IFM method to Copula parameters: reference Shih, etc. The proposed method of marginal distribution derivation (IFM) [27]. Given the marginal distribution function $F_{t}$ and $G_{t}$, the boundary distribution and the Copula to be evaluated parameters are respectively $\theta_{x}, \theta_{y}$ and $\theta_{C}$, the two-step estimation process is as follows:

The first step: the edge distribution parameters are estimated in turn by the maximum likelihood method.

$$
\begin{aligned}
& \hat{\theta}_{x}=\operatorname{argmax} \sum_{t=1}^{T} \log f_{t}\left(x_{t} \mid F_{t-1} ; \theta_{x}\right) \\
& \hat{\theta}_{y}=\operatorname{argmax} \sum_{t=1}^{T} \log g_{t}\left(y_{t} \mid G_{t-1} ; \theta_{y}\right)
\end{aligned}
$$

The second step: the parameters of the Copula are measured under the parameters of the marginal distribution based on the first step.

$$
\hat{\theta}_{c} \equiv \operatorname{argmax} \sum_{t=1}^{T} \log \left(c_{t}\left(u_{t}, v_{t} \mid F_{t-1}, \theta_{c}, \hat{\theta}_{x}, \hat{\theta}_{y}\right)\right)
$$

Then consider tail dependencies: the definition of Copula helps measure tail dependencies, that is, the probability of measuring the joint tail on or below the two variables. In a sense, the tail dependency coefficient is used to measure the trend of collapse or prosperity between markets. Upper and lower tail dependency coefficients $\lambda_{L}$ and $\lambda_{U}$ available two variables $X_{1}$ and $X_{2}$ Copula to express:

$$
\begin{array}{r}
\lambda_{L}=\lim _{q \rightarrow 0} \operatorname{Pr}\left[X_{1} \leq F_{1}^{-1}(q) / X_{2} \leq F_{2}^{-1}(q)\right]=\lim _{q \rightarrow 0} \frac{C(q, q)}{q} \\
\lambda_{U}=\lim _{q \rightarrow 1} \operatorname{Pr}\left[X_{1} \leq F_{1}^{-1}(q) / X_{2} \leq F_{2}^{-1}(q)\right]=\lim _{q \rightarrow 1} \frac{1-2 q+C(q, q)}{1-q}
\end{array}
$$

$F_{1}^{-1}$ and $F_{2}^{-1}$ is the marginal decimal function, $\lambda_{L}$ and $\lambda_{U} \in(0,1)$.

A large number of empirical studies show that there is often asymmetric tail correlation between financial markets, that is, tail correlation is stronger when the market collapses, and weaker when the city is rising [28,29]. In order to reflect the tail correlation in more detail, Ledford and tawn proposed a joint generation function method to depict the tail of the joint distribution [30], its conditional probability convergence speed Model:

$$
\operatorname{Pr}\{X>t, Y>t\} \sim \varphi(t) t^{-1 / \eta} \quad \mathrm{t} \rightarrow \infty
$$

Among them, $\varphi(t)$ for the slow change function, ${ }^{\eta}$ is the tail correlation coefficient, and ${ }^{\eta \in(0,1]}$, for the given ${ }^{\eta}, \varphi(t)$ expressed as relative strength, the two at the same time to depict the tail of the joint distribution, in describing the tail correlation is more detailed than the conditional probability.

In recent years, in view of the large number of literatures using a single parameter Copula which is difficult to portray at the same time to describe the correlation between the two variables, therefore, this paper adopts both single-parameter and double-parameter Copula unction to fit the asymmetric and thick tail characteristics of the two market.

\subsection{Simulated VaR and CVaR}

Fixed a confidence level to $1-\mathrm{q} \in(0,1)$ a random variable that $\mathrm{y} \in \mathrm{L}$, $\mathrm{L}$ is a natural distance of the matrix space, given as $\mathrm{d}(x, y):=\mathbb{E}(\operatorname{Max}\{|y-x|, 1\}) . \mathrm{P}$ is the probability density,

The $\operatorname{VaR}_{1-q}(y)$ given is as follows [33]:

$$
\operatorname{VaR}_{1-q}(y):=-\inf \{x \in \mathcal{R} ; \mathbb{P}(y \leq x)>q\}
$$




$$
\operatorname{CVaR}_{1-q}(y):=\frac{1}{q} \int_{0}^{q} \operatorname{VaR}_{1-t}(y) d t
$$

After simulating the risk value of random variables, in order to ensure its accuracy, it is necessary to carry out a backtest test, that is, to introduce Kupiec failure rate test. The backtest test method uses the failure rate to detect the accuracy of the VaR method. Ideally, the failure rate can be used to reflect the definition of VaR estimation to set the confidence level, The Kupiec LR based on likelihood rate verifies that the failure rate is consistent with the given confidence level. If $\mathrm{N}$ is a value that exceeds $\mathrm{VaR}$ and $\mathrm{T}$ is the total sample, which is a P significant level, it is assumed that the Kupiec LR test is: $H_{0}: p=N / T, H_{1}: p \neq N / T$

The statistics of the Kupiec LR test are $L R_{U C}$ :

$$
L R_{U C}=2\left[\log \left(\left(\frac{N}{T}\right)^{N}\left(1-\frac{N}{T}\right)^{T-N}\right)-\log \left(p^{N}(1-p)^{T-N}\right)\right]
$$

\begin{tabular}{|c|c|c|c|c|c|c|}
\hline Category & Function & Related structural forms & \multicolumn{2}{|c|}{ Upper tail } & \multicolumn{2}{|c|}{ Lower tail } \\
\hline \multirow{2}{*}{$\begin{array}{l}\text { Archimax } \\
\text { Copula }\end{array}$} & \multirow{2}{*}{ BB4 } & \multirow{2}{*}{$\begin{array}{c}C(u, v)=\varphi^{-1}[(\varphi(u)+\varphi(v)) A(\varphi(u) /(\varphi(u)+\varphi(v)))](1) \\
\text { style } \\
\text { At that time, the (1) formula was transformed } \\
\text { into (2) }\end{array}$} & $\eta$ & $\varphi(t)$ & $\eta$ & $\varphi(t)$ \\
\hline & & & 1 & $2^{-1 / \delta}$ & 1 & $\left(2-2^{-1 / \theta}\right)^{-1 / \delta}$ \\
\hline \multirow{6}{*}{$\begin{array}{l}\text { Archimedean } \\
\text { Copula }\end{array}$} & BB1 & \multirow{6}{*}{$\begin{array}{c}C(u, v)=\varphi^{[-1]}[\varphi(u)+\varphi(v)](2) \text { style } \\
\varphi:(0,1] \rightarrow[0, \infty) \text { As a convex function } \\
\varphi^{[-1]}(t)= \begin{cases}\varphi^{-1}(t), 0 \leq t \leq \varphi(0) \\
0, & \varphi(0) \leq t<\infty\end{cases} \end{array}$} & 1 & $2-2^{1 / \delta}$ & 1 & $2^{-1 / \theta \delta}$ \\
\hline & BB3 & & 1 & $2-2^{1 / \theta}$ & 1 & 1 \\
\hline & BB7 & & 1 & $2-2^{1 / \theta}$ & 1 & $2^{-1 / \delta}$ \\
\hline & BB2 & & 0.5 & $\theta(\delta+1)+1$ & 1 & 1 \\
\hline & Clayton & & 0.5 & $1+\delta$ & 0.5 & $2^{-1 / \delta}$ \\
\hline & Joe & & 1 & $2-2^{1 / \delta}$ & 0.5 & $\delta$ \\
\hline $\begin{array}{l}\text { Elliptic } \\
\text { Copula }\end{array}$ & $\begin{array}{l}\text { Gumbel } \\
\text { Frank } \\
\text { Gaussian }\end{array}$ & $\begin{array}{c}C_{G}\left(u_{1}, u_{2}, \delta\right)=\exp \left\{-\left[-\left(-\log u_{1}\right)^{\delta}\right.\right. \\
\left.\left.+\left(-\log u_{2}\right)^{\delta}\right]^{1 / \delta}\right\} \\
C_{F}\left(u_{1}, u_{2}, \theta\right)=-\frac{1}{\theta} \log \\
=\frac{1}{\theta} \log \left[\frac{\theta\left(1-e^{-\theta}\right)-\left(1-e^{-\theta u}\right)\left(1-e^{-\theta v}\right)}{1-e^{-\theta}}\right] \\
C_{N}\left(u_{1}, u_{2}, \rho\right)=\varnothing\left[\varnothing^{-1}\left(u_{1}\right), \emptyset^{-1}\left(u_{2}\right)\right]\end{array}$ & & $\begin{array}{l}0 \\
0 \\
0\end{array}$ & \multicolumn{2}{|r|}{$\begin{array}{c}2-2^{1 / \delta} \\
0 \\
0\end{array}$} \\
\hline
\end{tabular}

Table 1 Copula clusterfunction and tail correlation coefficient and slow change function.

Note: Data collation comes from Harry Joe [31] and Janet E. heffernan [32].

\subsection{Simulated VaR and CVaR}

Fixed a confidence level to $1-\mathrm{q} \in(0,1)$ a random variable that $\mathrm{y} \in \mathrm{L}$, $\mathrm{L}$ is a natural distance of the matrix space, given as $\mathrm{d}(x, y):=\mathbb{E}(\operatorname{Max}\{|y-x|, 1\})$. $\mathrm{P}$ is the probability density,

The $\operatorname{VaR}_{1-q}(y)$ given is as follows [33]:

$$
\begin{array}{r}
\operatorname{VaR}_{1-q}(y):=-\inf \{x \in \mathcal{R} ; \mathbb{P}(y \leq x)>q\} \\
\operatorname{CVaR}_{1-q}(y):=\frac{1}{q} \int_{0}^{q} \operatorname{VaR}_{1-t}(y) d t
\end{array}
$$

After simulating the risk value of random variables, in order to ensure its accuracy, it is necessary to carry out a backtest test, that is, to introduce Kupiec failure rate test. The backtest test method uses the failure rate to detect the accuracy of the VaR method. Ideally, the failure rate can be used to reflect the definition of VaR estimation to set the confidence level, The Kupiec LR based on likelihood rate verifies that the failure rate is consistent with the given confidence level. If $\mathrm{N}$ is a value that exceeds $\mathrm{VaR}$ and $\mathrm{T}$ is the total sample, which is a P significant level, it is assumed that 
the Kupiec LR test is: $H_{0}: p=N / T, H_{1}: p \neq N / T$

The statistics of the Kupiec LR test are $L R_{U C}$ :

$$
L R_{U C}=2\left[\log \left(\left(\frac{N}{T}\right)^{N}\left(1-\frac{N}{T}\right)^{T-N}\right)-\log \left(p^{N}(1-p)^{T-N}\right)\right]
$$

\section{Empirical Analysis}

\subsection{Selection and statistical characteristics of samples}

Considering that the year is the basic completion of China's share division reform, the United States subprime mortgage crisis initially appeared, in order to fully depict the 2008 year World financial crisis and 2015 years before and after the huge fluctuation of China's securities market QFII investment strategy, selection the QFII shareholding index compiled by great wisdom company, which selects the listed company with QFII shareholding as the constituent stock, is compiled by the pie weighting. Therefore, this article is selected from 2006.9.17 to 2018.7.1 days of QFII shareholding Index and Shanghai and Shenzhen index day data closed ${ }^{{ }_{t}}$ as a study sample, a total of 2857 Group valid data, the overall correlation coefficient is 0.9323 . The sample estimated interval was 2006.9.1 to 2018.7.1, with a total 2857 group sample data(for better characterization of the two index, two sub-samples are also divided, see 3.3), The sample post-test interval is 2015.6.3 to 2018.7.1, a total of 1008 daily closing data, data from Great Wisdom Software and Rui Si Database. Considering sequence smoothness, the daily logarithmic yield of the two indices is defined as: ${ }^{X_{t}}=\ln p_{t}-\ln p_{t-1}$.
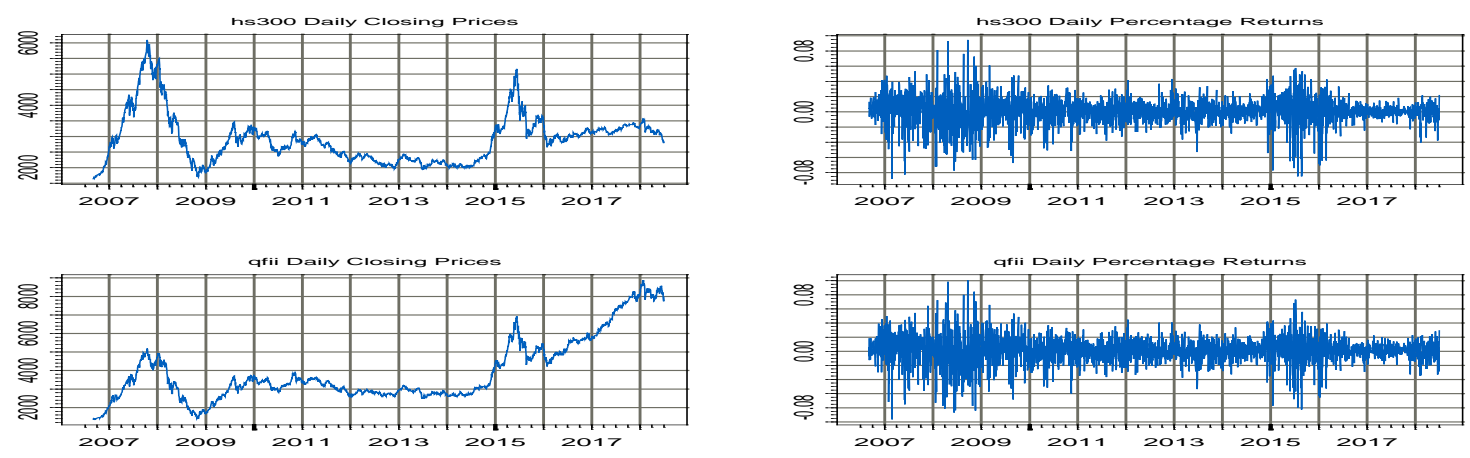

Figure 1 price and yield maps for HS300 and QFII (sample range of 2006.9-2018.7)

In Figure 1, the top left and bottom diagrams visually show the price trends of the HS300 and QFII sample ranges, with large fluctuations in both indices in 2007-08 and 2015-16, although the two showed convergent characteristics in the 2007-08 world financial crisis. However, the difference is that in the 2015 market fluctuation, the QFII index amplitude is much smaller than the HS300 index, and in the subsequent market rebound performance is far better than the HS300 index, indicating that the investment effect is better, the value investment strategy is more obvious. Can be understood as on the one hand, the allocation of funds is better, on the other hand, in the value of stocks far below its value, QFII dare to reverse the trend, once the market expectations improve, the benefits are significantly dominant. The top right and the following figures are HS300 and QFII, respectively indices volatility, manifested in the following: One was characterized by high volatility during the 2008 global financial crisis, but in 2015 market volatility presented a new feature, namely, in the country funds into the market after that, the market volatility is significantly reduced, indicating the return of investor value concept and tend to be rational. Market volatility began to rise again in 2018 due to uncertainty about the outlook for the Sino-US trade war. Second, in the 2015 market deep adjustment, QFII is not only lower than the HS300 index volatility in the same period, but also well below the 2008 world financial tsunami volatility level, indicating that QFII uphold the value of investment philosophy, did not follow the market chase rise and fall. QFII uphold value investment in Figure 1 the overall performance of lower volatility, less extreme 
fluctuations, fluctuating clustering and thick tail characteristics have decreased, these visual displays need to further use the extreme value theory of the GPD model combined with marginal distribution in-depth exploration.

As the Table 2 shows, QFII and HS300 yield mean is small, the standard deviation is large, the deviation negative means that the negative impact of the two sequences is more intense than the positive impact. Peak is greater than 3 , JB hypothesis test indicates non-compliance with normal distribution, ADF test is 0 . The stochastic process of order smoothness. Ljung-box statistics show that there $Q(k)$ is a weak sequence autocorrelation, and the $Q^{2}(k)$ test shows that the square autocorrelation of yield is stronger, The statistics show that the sequence nonlinear dependencies have conditional heteroscedasticity, which is shown as volatility clustering in figure 1 , and obviously in the huge fluctuation of annual volatility in the year of 0.15 and 2, the downward fluctuation is higher than the upward fluctuation, which can Consider modeling with an asymmetric ASV model. Therefore, the yield sequences of both indices are left bias, thick tail but stable distribution.

Then the ASVmodel is used to fit the income sequence of the two index, eliminate its conditional variance and obtain the unobservable wave rate sequence, based on the MCMC a sample of Gibbs 50000 times, the parameter estimation results of the ASV model see table 3.

Table 2 statistical characteristics of yield oF HS300 and QFII samples

\begin{tabular}{|c|c|c|c|c|c|c|c|c|}
\hline Index & $\begin{array}{c}\text { ADF } \\
\text { Inspection }\end{array}$ & $\begin{array}{c}\text { Mean } \\
\text { value }\end{array}$ & $\begin{array}{c}\text { Standard } \\
\text { deviation }\end{array}$ & $\begin{array}{c}\text { Degree } \\
\text { of bias }\end{array}$ & $\begin{array}{c}\text { Peak } \\
\text { degree }\end{array}$ & $\begin{array}{c}\text { J-B } \\
\text { Inspection }\end{array}$ & Q(20) & Q2(20) \\
\hline HS300 & $-52.11(0.0001)$ & 0.00019 & 0.00947 & -0.6309 & 7.319 & $2411.3(0)$ & $61.19(0)$ & $733.26(0)$ \\
\hline QFII & $-51.92(0.0001)$ & 0.00096 & 0.01826 & -0.5473 & 6.784 & $1847.7(0)$ & $64.29(0)$ & $600.46(0)$ \\
\hline
\end{tabular}

Table 3 Parameter estimation results of ASV model

\begin{tabular}{|c|c|c|c|c|c|c|c|c|}
\hline Market & \multicolumn{4}{|c|}{ QFII shareholding Index } & \multicolumn{3}{|c|}{ Shanghai and Shenzhen 300 index } \\
\hline Parameters & $\begin{array}{c}\text { Mean } \\
\text { value }\end{array}$ & $\begin{array}{c}\text { Standard } \\
\text { deviation }\end{array}$ & $\begin{array}{c}\text { MC } \\
\text { Standard } \\
\text { deviation }\end{array}$ & $\begin{array}{c}\text { 95\% } \\
\text { Confidence } \\
\text { Interval }\end{array}$ & $\begin{array}{c}\text { Mean } \\
\text { value }\end{array}$ & $\begin{array}{c}\text { Standard } \\
\text { deviation }\end{array}$ & $\begin{array}{c}\text { MC } \\
\text { Standard } \\
\text { deviation }\end{array}$ & $\begin{array}{c}\text { 95\% } \\
\text { Confidence } \\
\text { Interval }\end{array}$ \\
\hline M & -0.3264 & 0.2168 & 0.0028 & $(-0.7633,0.1248)$ & -0.3804 & 0.2419 & 0.0033 & $(-0.8455,0.0469)$ \\
\hline F & 0.9789 & 0.0044 & $2.36 a n d-4$ & $(0.9590,0.9915)$ & 0.9866 & 0.0041 & $2.15 a n d-4$ & $(0.9783,0.9908)$ \\
\hline$\rho$ & 41.81 & 13.93 & 1.0014 & $(16.84,75.19)$ & 54.73 & 25.66 & 1.737 & $(25.44,136.80)$ \\
\hline$\rho$ & -0.2209 & 0.0781 & 0.0038 & $(-0.3921,0.0419)$ & -0.1582 & 0.1017 & 0.0051 & $(-0.3276,0.0611)$ \\
\hline
\end{tabular}

As we know from Table 3, the convergence of Geweke spectral density is tested by the CODA sequence of parameter estimation, and the structure, the $t$ statistic 1.0278 is less than the critical value of 2. Therefore, the sample sequence of simulated MCMC method is stable and convergent, parameter estimates are valid. At the same time, the parameters of QFII and HS300 yield sequences $\rho$ are negative, the results show that there is a significant asymmetric leverage effect between the two indexes in the estimated sample period. Refer to the literature [17] and then substitute the parameter estimation results (2), you can get progressive independence and distribution. Of the standard residuals sequence (The statistical characteristics are shown in the table 4), and then applications POT Models to model them.

Table 4 Statistical characteristics of standard RESIDUALS sequences for HS300 and QFII samples

\begin{tabular}{|c|c|c|c|c|c|c|c|c|c|}
\hline Index & \multicolumn{5}{|c|}{ Sample decimal digits } & \multicolumn{4}{c|}{ Sample Moment } \\
\hline & Minimum & $25 \%$ & Median & $75 \%$ & Biggest & $\begin{array}{c}\text { Mean } \\
\text { value }\end{array}$ & $\begin{array}{c}\text { Standard } \\
\text { deviation }\end{array}$ & $\begin{array}{c}\text { Degree } \\
\text { of bias }\end{array}$ & $\begin{array}{c}\text { Peak } \\
\text { degree }\end{array}$ \\
\hline HS300 & -0.0884 & -0.0066 & 0.0009 & 0.0084 & 0.0946 & 0.0003 & 0.0169 & -0.4796 & 7.156 \\
\hline QFII & -0.0964 & -0.0071 & 0.0009 & 0.0102 & 0.1005 & 0.0008 & 0.0182 & -0.3973 & 6.633 \\
\hline
\end{tabular}

The dependencies of the standard residuals sequences of the two indices are discussed below. After calculating its linear correlation coefficient ${ }^{\rho}=0.93$, the rank correlation coefficient $\rho_{s}=0.9$, 
Kendall $\tau=0.7635$, QFII and HS300 there is a strong linear correlation between the standard residuals sequences, which shows that it is meaningful to study the correlation between the two indices. If you compare the scatter plot of the two index standard residuals with the simulation diagram of the two yuan normal distribution of the mean and covariance constructs (limited to length, no illustration), Obviously, based on the normal distribution hypothesis, it is obviously inaccurate to describe the distribution of the standard residual sequence of two index, which indicates that the use of linear correlation coefficients to measure dependencies may produce misleading results.

\subsection{Edge distribution model}

\subsubsection{Parameter estimation}

When using the POT model to fit the GPD distribution, a general range of thresholds can be determined first, taking into account the strong subjectivity of the MEF graph selection threshold (see Figure 2), and then the peak method is used to select the threshold value quantitatively.
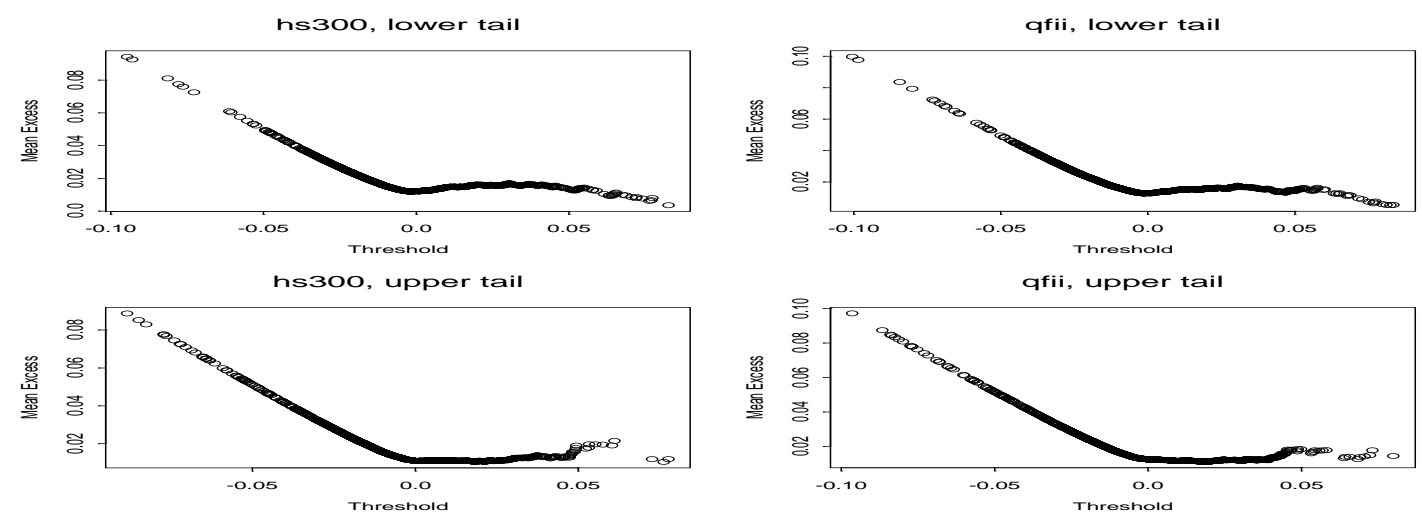

Figure 2 MEF diagram of sample standard residuals sequences for HS300 and QFII.

After the threshold is determined, the shape parameters $\xi$ and $\beta$ scale parameters in GPD are estimated by the maximum likelihood method, and when the shape parameters are estimated, the lower end of the two index is used as an example to adopt the information-rich shape diagram, figure 3 based on threshold observation, the shape parameter range can be roughly determined, and the shape parameters are positive, indicating that the standard residual sequence of the two indices obeys the tail GPD I type distribution.
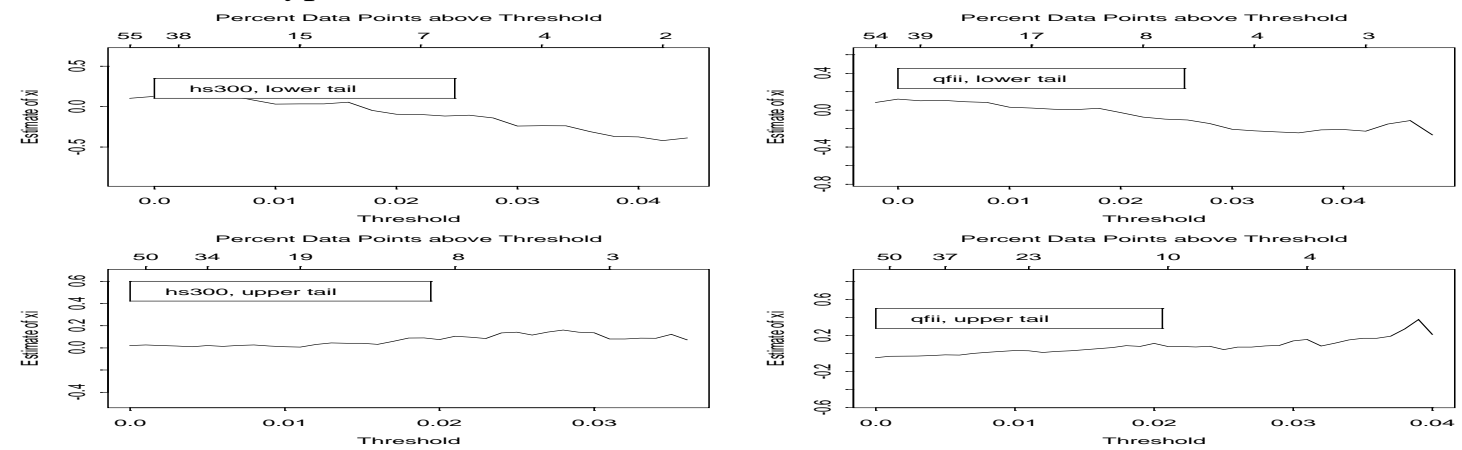

Figure 3 shape diagram of the lower end of the sample standard residuals sequence for HS300 and QFII

The estimation results of thresholds and parameters are shown in table 5 below, and based on the literature [19], the GPD distribution, although not satisfying the regular conditions, However, it does not affect its application in the extremum model, and the peak coefficient value is close to the upper limit of 3. It is indicated that the GPD distribution well fits the standard residual sequence of the two indices.

Table 5 Estimation results of thresholds and GPD parameters 


\begin{tabular}{|c|c|c|c|c|c|c|c|c|c|c|}
\hline \multirow[b]{2}{*}{ Index } & \multirow[b]{2}{*}{ Tail } & \multirow{2}{*}{$\begin{array}{c}\text { Threshold } \\
\text { value }\end{array}$} & \multirow{2}{*}{$\begin{array}{l}\text { Exceeding } \\
\text { threshold } \\
\text { value } \\
\text { Proportion }\end{array}$} & \multirow{2}{*}{$\begin{array}{c}\text { Peak } \\
\text { coefficient }\end{array}$} & \multicolumn{3}{|c|}{ Shape parameters $\xi$} & \multicolumn{3}{|c|}{ Scale parameters $\beta$} \\
\hline & & & & & $\begin{array}{c}\xi \\
\text { Value }\end{array}$ & $\begin{array}{l}\text { Standard } \\
\text { error }\end{array}$ & $t_{\text {Value }}$ & $\begin{array}{c}\beta \\
\text { Value }\end{array}$ & $\begin{array}{l}\text { Standard } \\
\text { error }\end{array}$ & $t_{\text {Value }}$ \\
\hline \multirow[b]{2}{*}{ QFII } & Ageo & 0.0169 & $14.46 \%$ & 2.9941 & 0.0730 & 0.0866 & -0.7538 & 0.0104 & 0.0019 & 6.8207 \\
\hline & $\begin{array}{c}\text { Lower } \\
\text { tail }\end{array}$ & -0.0164 & $12.32 \%$ & 2.9932 & 0.0127 & 0.1534 & -1.9893 & 0.0150 & 0.0028 & 6.6480 \\
\hline \multirow[b]{2}{*}{ HS300 } & Ageo & 0.0158 & $12.92 \%$ & 2.9956 & 0.0485 & 0.0972 & -1.6702 & 0.0105 & 0.0011 & 6.7331 \\
\hline & $\begin{array}{c}\text { Lower } \\
\text { tail }\end{array}$ & -0.0148 & $12.64 \%$ & 2.9945 & 0.0281 & 0.1184 & -3.6271 & 0.0144 & 0.0021 & 8.1422 \\
\hline
\end{tabular}

\subsubsection{Fitting inspection}

In order to verify the validity of the GPD model, the HS300 Upper tail index and the QFII Lower tail index are fitted respectively.

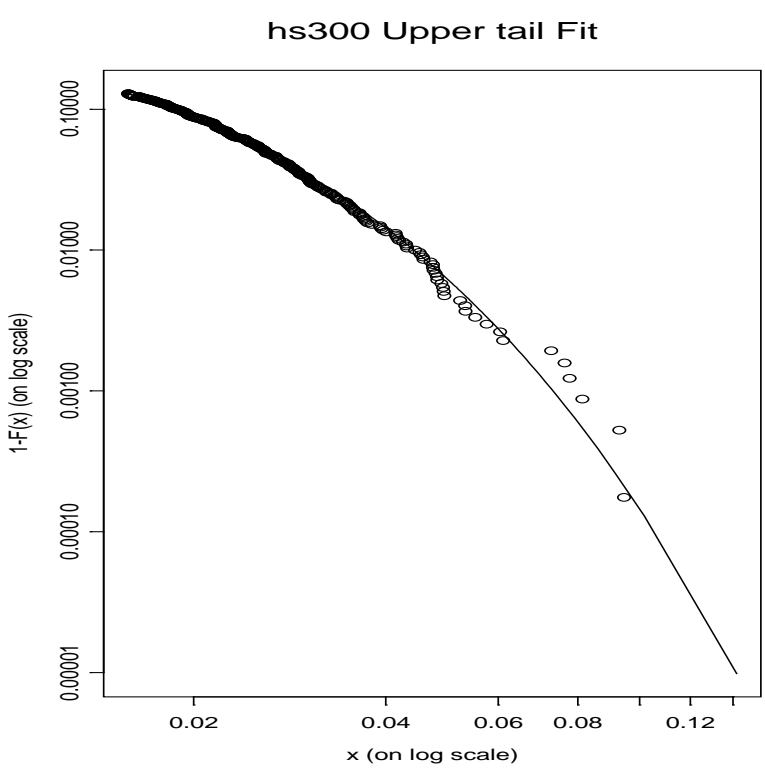

(1) HS300 Upper Tail Fitting

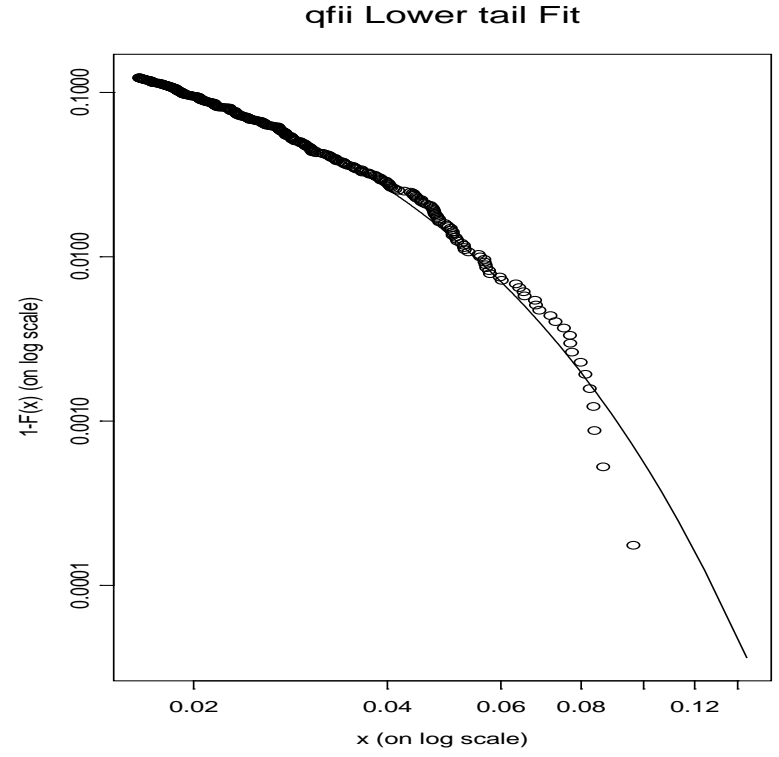

(2) QFII Lower tail Fitting

Figure 4 GPD fitting diagnostic diagram of the upper and lower tail of the standard residual sequence of two indices.

Figure 4 intuitively shows that, with the exception of very few points, the GPD model fits the HS300 and QFII well. The upper of the standard residuals sequence, the next tail extremum. Limited to space, the GPD model also fits well into the lower tail of HS300 and QFII of the on the tail extremum.

\subsection{Selection and fitting optimization test of Copula}

The key to accurately depict the correlation structure between financial time series is to select the optimal Copula function so that it describes the nonlinear and asymmetric tail correlation between variables according to the characteristics of the model. For example, in the case of the Gumbel of extreme Copula, Based on its parameters, we use Monte Carlo to simulate the density and cumulative distribution of HS300 and QFII, and to build the density and cumulative distribution contour of the two variables based on Gumbel. The process is as follows: first, the parameters of the double variable Gumbel Copula are obtained by the variance-covariance matrix of the whole estimated sample as 4.16, And then the kernel density estimation is carried out based on the kernel definition and the selected window width, and the window width is set to 0.2648 and 0.2617 respectively. The results of the simulation are shown in the figure 5, Figure 5 display the estimated core density of single peak, fitting accuracy higher. Obviously, the higher the dimension, the larger the sample, the easier it is to get a reasonable nuclear density estimate.

The parameter estimation methods commonly used in Copula function are: Maximum likelihood estimation method (MLE), edge distribution derivation method (IFM)[34] In the case of MLE 
method, It is often difficult for the estimation parameters to converge to the extreme point, and the IFM method, without reducing the efficiency, The calculation is simpler, so the IFM method is used to estimate the parameters of the optimal Copula function, that is, the first estimate the parameters of the edge distribution first, and then estimate the parameters of the Copula.
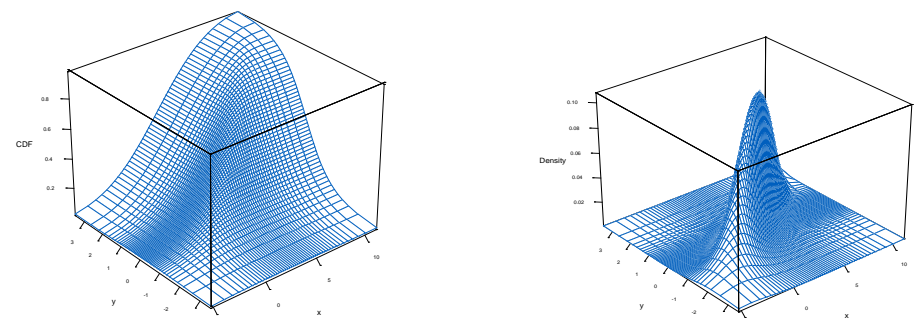

Figure 5 HS300 and QFII based on Gumbe parameter simulation density and cumulative distribution of maps

Table 6 parameter estimation and model test results in Copula clusters.

\begin{tabular}{|c|c|c|c|c|c|c|c|}
\hline Copula Clusters & Copula name & $\boldsymbol{\delta}$ & $\theta$ & Likelihood value & AIC & BIC & HQ \\
\hline Archimax & BB4 & 2.2190 & 0.9422 & 2993.6 & -5983.1 & -5971.2 & -5978.8 \\
\hline Copulas & Frank & $14.95(48.19)$ & & 2605.7 & -5209.4 & -5203.4 & -5207.2 \\
\hline & Joe & & $4.5065(--)$ & 2292.9 & -4583.8 & -4577.8 & -4581.6 \\
\hline & BB1 & 2.9053 & 0.9675 & 3012.9 & -6021.9 & -6010.1 & -6017.6 \\
\hline & BB2 & 12017.2 & 0.003 & 2080.6 & -4157.3 & -4145.1 & -4152.9 \\
\hline Archimedean & BB3 & 2.1824 & 1.4182 & 2817.8 & -5631.6 & -5619.7 & -5627.3 \\
\hline Copulas & BB6 & 1.0000 & 4.2921 & 2280.1 & -4556.3 & -4544.4 & -4552.1 \\
\hline & BB7 & 4.0092 & 3.6538 & 2945.2 & -5886.3 & -5974.4 & -5882.1 \\
\hline & Clayton & $4.6093(48.79)$ & & 2528.3 & -5054.5 & -5048.6 & -5052.4 \\
\hline & Gumbel & $4.0574(63.02)$ & & 2808.5 & -5614.9 & -5609.1 & -5612.8 \\
\hline & Galambos & $3.3370(52.54)$ & & 2789.9 & -5577.8 & -5571.8 & -5575.7 \\
\hline EV Copulas & Husler.reiss & $3.6477(67.08)$ & & 2612.9 & -5223.8 & -5217.8 & -5221.6 \\
\hline & Tawn & $\alpha=0.9875, \beta=0.9826$ & $\gamma=4.3615$ & 2844.3 & -5682.6 & -5664.8 & -5676.2 \\
\hline & BB5 & 3.3370 & 1.0000 & 2789.9 & -5575.8 & -5563.9 & -5571.5 \\
\hline Elliptic Copula & Normal & $0.9261(474.1)$ & & 2784.9 & -5567.8 & -5561.9 & -5612.8 \\
\hline
\end{tabular}

Note: The black body in the table is fitted with the optimal single and double parameter Copula, () is the statistical T value, (-) is unable to fit the $\mathrm{T}$ value.

As can be seen from table 6, based on the maximum criterion of likelihood function and the minimum criterion of AIC, BIC and HQ, the single-parameter structure of fitting Copula, Normal, Gumbel, Galambos, Husler. reiss, Frank, and Joe fitting, Gumbel fitting the best fit, Joe is the worst; The worst of the two-parameter structure fitting is BB2, which does not display the graph, and then selects the second difference BB6. All single-parameter and double-parameter Copula functions given in the whole sample are fitted with the optimal BB1 copula, indicating that the optimal

Copula selection depends on the structure of the sample itself. Limited to space, it should be stated that we divide the entire sample range into two parts to fit separately (2006.9-2012.1 and 2012.2-2018.7), two samples fitted with optimal double parameters Copula remains the BB1 Copula, Which is consistent with the fitting of the entire sample interval. But the difference is that in the sample (2006.9-2012.1) interval, the optimal single parameter is fitted copula for Frank Copula; in the sample (2012.2-2018.7) interval, fitted with the optimal single parameter Copula for Normal Copula, while the entire sample interval fits the optimal single-parameter Copula is Gumbel Copula.

Refer to figure 6, double parameter BB1 Copula compared to Gumbel Copula, can provide more accurate and robust fitting experience Copula effect, so choose BB1 Copula to depict QFII and the correlation structure of the HS300 standard residuals sequence is appropriate, and its corresponding parameters $\delta=2.9053, \theta=0.9675$. Therefore, when using the Copula method to simulate the correlation of two variables, if only single or double parameter Copula function structure or subjective choice is considered several, the Copula function may come to the wrong conclusion, but we should consider four kinds of Copula cluster single parameters and the Copula function of 
double parameter, to describe the dependent structure of random variables.

Copula Empirical vs. Fitted CDF

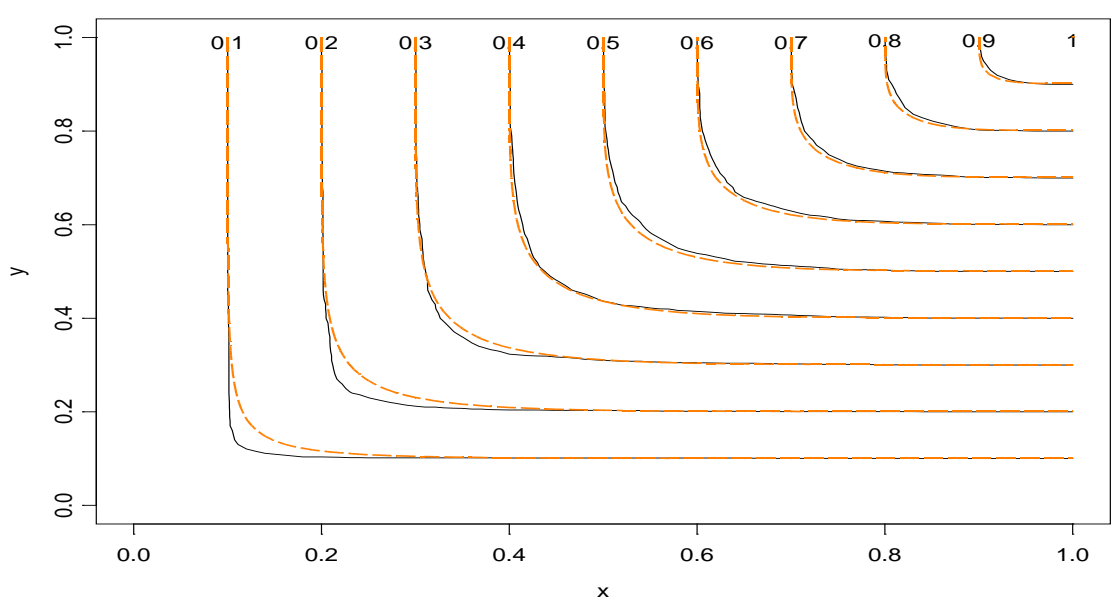

(1) Gumbel Copula and Experience Copula The fitting CDF Diagram Copula Empirical vs. Fitted CDF

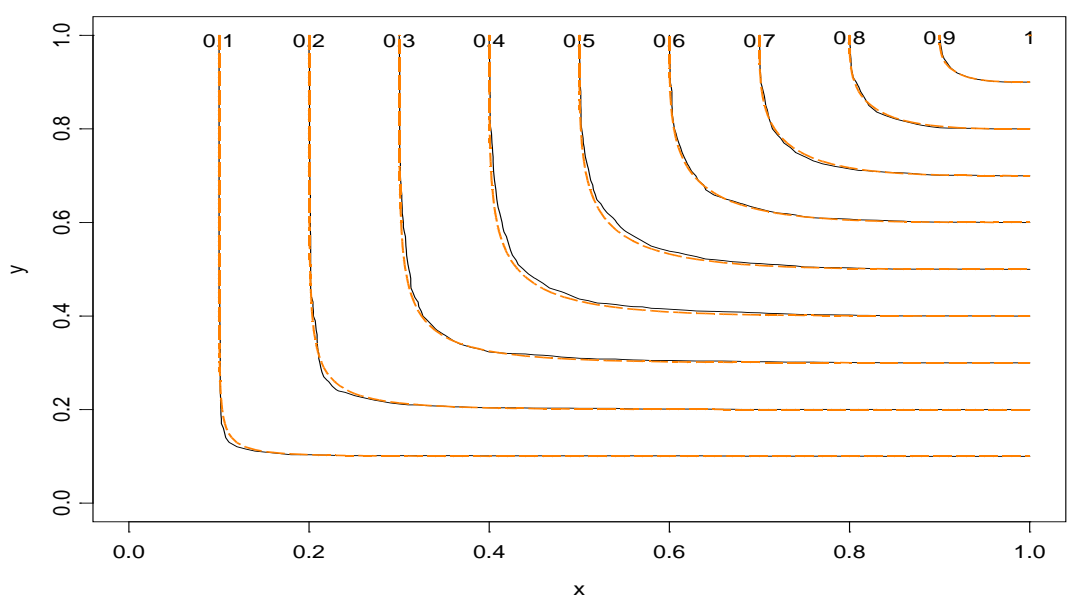

(2) Fitting CDF diagram of BB1 Copula and experience Copula Copula Empirical vs. Fitted CDF

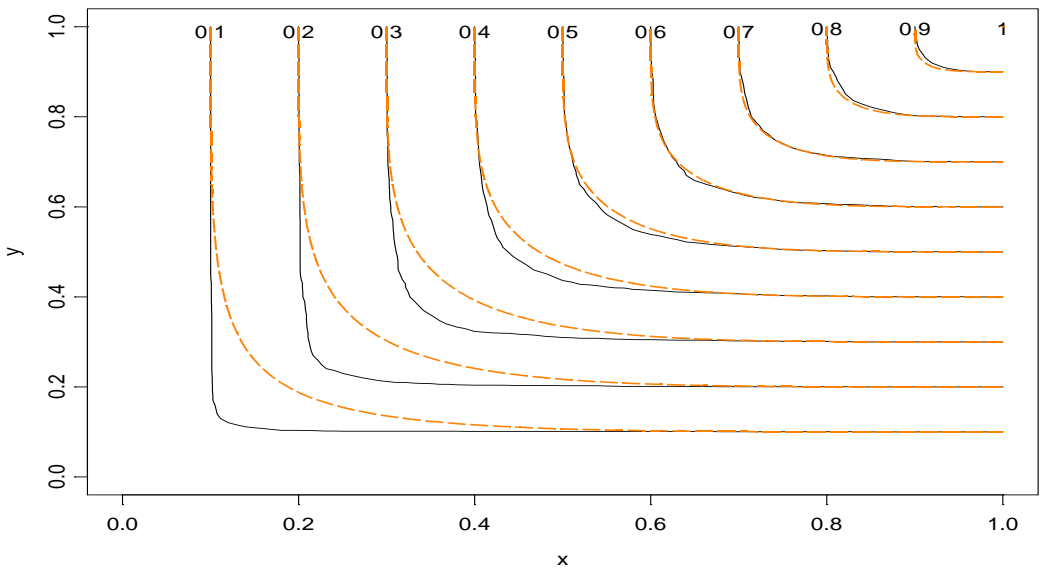

(3) Joe Copula and Experience Copula the fitting CDF Diagram 
Copula Empirical vs. Fitted CDF

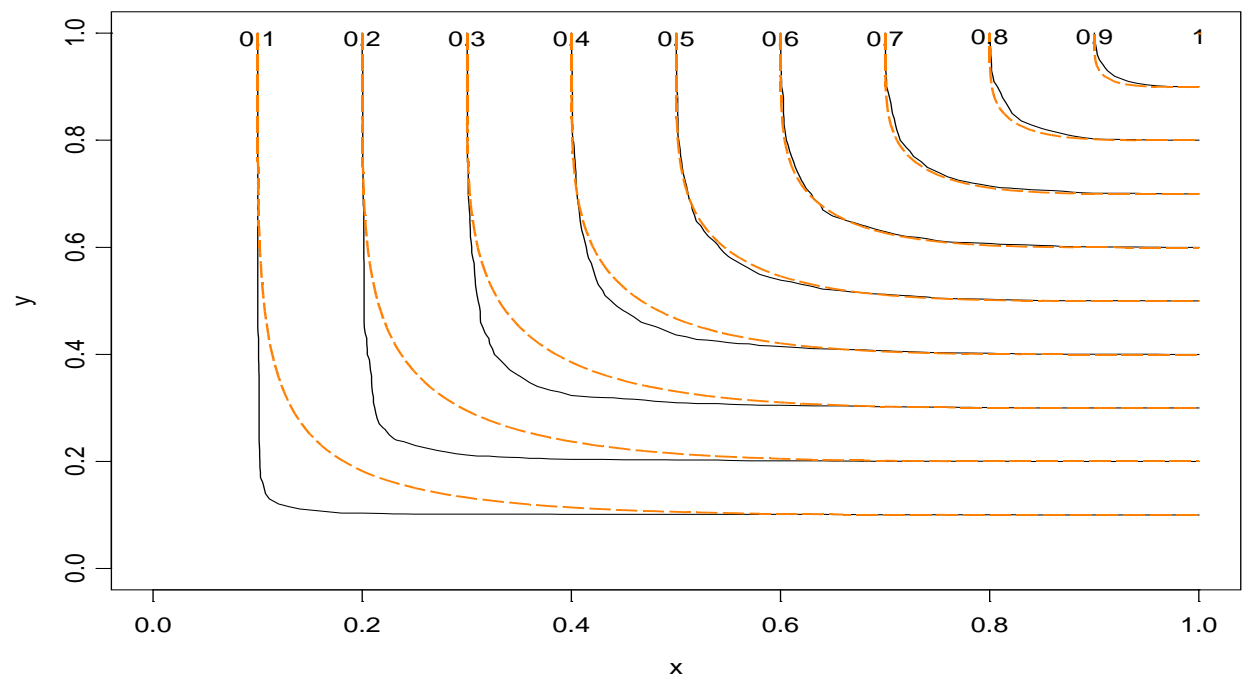

(4) BB6 Copula and Experience Copula the fitting CDF

Figure 6 Copula and experience Copula fitting CDF effect for QFII and HS300 related structures Contrast diagram.

\subsection{Risk metrics for tail correlation measurements and Monte Carlo Simulations}

Tail correlation coefficient is a measure widely used in extreme value theory, which is often used to show that when a random variable is extreme, another variable also appears the probability of extreme value. In order to describe the correlation of the tail in detail, the joint generation function method of reference Ledford and Tawn BB1 Copula. The tail correlation coefficient is solved, and the upper tail correlation coefficient and the slow change function are respectively $\eta_{u=1,} \varphi(t)^{u}=2-2^{1 / \delta}$ $=0.7306$, this means that, if HS300 the index exceeds a certain value that appears to jump upward, accordingly, QFII the probability of a price jump up beyond a certain value is $73.06 \%$; The correlation coefficient and the slow change function of the lower tail are respectively. $\eta_{l}=1$ $\varphi(t)^{l}=2^{-1 / \theta \delta}=0.7814$. Similarly, if the HS300 exceeds a certain value and the price jumps down, the QFII exceeds the corresponding. The probability of a certain value appearing down price jumps is $78.14 \%$. Thus, the asymptotic correlation of the upper and lower tail and the relative strength of the lower tail are higher than that of the upper tail, indicating that the correlation between the two indicesin decline is significantly higher than that of its rise. This is consistent with the findings of studies such as Longin F and Ang A, contrary to the findings of Karmakar M.

According to the previous analysis, after determining BB1 as the optimal Copula, through QFII and HS300.The estimated samples are constructed to set equal weight combinations, the benefits of which are defined as, and respectively, where ${ }^{x=\ln \left(P_{1, t+1} / P_{t}\right)}$ and ${ }^{y=\ln \left(P_{2, t+1} / P_{2, t}\right)}$ are the logarithmic gains of QFII and HS300, given the probability of loss is ${ }^{1-q}$ and the distribution function is,then $\operatorname{VaR}_{q}=F_{-r}^{-1}(q), C V a R_{q}=E\left(-r \mid-r>V a R_{q}\right)$. Simulation program through Monte Carlo simulation 10000 independent Uniform variable, This variable comes from the optimal BB1 copula function of the estimation parameters, and then will be their convert to a standard residuals sequence. The residuals sequence is then imported into the ASV-GPD model, simulation out QFII and HS300.The exponential combination at a given confidence level $\mathrm{VaR}$ and $\mathrm{CVaR}$, Finally, the simulated risk value is compared with the combination of calculations. The yield sequence is carried out analysis, the results are shown in table 7 , and then the risk value of the numerical simulation is carried out through the posterior sample to use kupiec backtest test, The results show that the failure times of 
$\mathrm{VaR}$ are in non-rejection domain, the LR value is lower than the critical value and the corresponding probability value is significantly higher than the set loss probability value, which indicates that the risk measure based on BB1 Copula is better.

Table 7 Based on the BB1 copula model for the risk measurement of QFII and HS300 indexstandard residuals sequences.

\begin{tabular}{|c|c|c|c|c|c|}
\hline Confidence degree & $95 \%$ & $97.5 \%$ & $99 \%$ & $99.5 \%$ & $99.9 \%$ \\
\hline Was & 0.0294 & 0.0395 & 0.0522 & 0.0580 & 0.0821 \\
\hline Cvar & 0.0430 & 0.0524 & 0.0635 & 0.0723 & 0.0953 \\
\hline $\begin{array}{c}\text { VaR post-Test } \\
\text { acceptance domain }\end{array}$ & $37<\mathrm{N}<65$ & $15<\mathrm{N}<36$ & $4<\mathrm{N}<17$ & $\mathrm{~N}<4$ & $0 \leq \mathrm{N}<1$ \\
\hline $\begin{array}{c}\text { Actual number of } \\
\text { failures }\end{array}$ & 43 & 16 & 6 & 1 & 0 \\
\hline LR Statistics & 1.2742 & 0.0374 & 0.7482 & 0.0739 & 0.5208 \\
\hline P Probability value & 0.2391 & 0.8613 & 0.4526 & 0.7944 & 0.4902 \\
\hline
\end{tabular}

Note: The critical values of LR under each sub-position are 3.84, 5.02, 6.63, 7.88 and 10.83, respectively. The LR is less than the critical value, the $\mathrm{P}$ value is the probability of not rejecting the domain, and the confidence degree ${ }^{1-q}$, $\omega_{1}, \omega_{2}$ is the weight of the build combination.

\section{Conclusion}

Selected 2006.9.1 to 2018.7.1 QFII shareholding Index and Shanghai and Shenzhen the daily data of the statistics index are the research object, using four kinds of the correlation between two indexes was studied by Copula cluster method, and the empirical results showed that:

(1) From the correlation of two index, the Spielman rank correlation coefficient is up to 0.9323, which indicates that the two indices have a strong correlation and a very high degree of overlap, QFII the yield sequence 2015 huge fluctuations of the year. After overlapping innovation high, far better than HS300 the performance of the index. This shows that QFII has been adhering to the value of investment strategy. By using the joint generation function method to analyze the tail correlation coefficient of the optimal BB1 Copula, it is shown that the two-index tail is stronger than the 0.8 , and has obvious asymmetry, That is, the correlation in the downturn is higher than the correlation of its active period, which indicates that the negative extremum income makes the two indexes have a higher correlation;

(2) In the overall sample interval, double parameter BB1 copula basis AIC the overall criteria are superior to single and double parameters. Copula function, and single parameter Copula optimal single parameters for elective of overall samples and fine molecular samples Copula are different. Therefore, BB1 Copula well depicts the tail correlation nonlinear, thick tail and asymmetric characteristics of the two index standard residuals, and the correlation structure fitting is better than others. On this basis, then the two index and other rights reorganization combined to simulate its risk value, the backtest test shows that the BB1 Copula-ASV-GPD of the the statistics of each index are within the reasonable limit, the risk measurement effect is good, which is consistent with the visual display of our aforementioned two index yield sequence.

The empirical results of this paper show that the management implements the rationality of increasing QFII approval and paying attention to the reasonable dividend policy, and at the same time, under the new economic normal, according to the new characteristics and new trends of the securities market, The whole securities market presents new characteristics such as low fluctuation, less clustering and low thick tail, but it still presents asymmetric characteristics and pays more attention to the fundamental investment of each stock. This new feature and new trend is conducive to the promotion of value investment concept and strategy. To carry out the value investment strategy, we should actively encourage the listing of high-quality large-cap blue chips, effectively protect the interests of small and medium-sized investors, and achieve the desired objectives. After all, listed companies are the fundamental of a country's securities market, only to effectively improve the overall quality of listed companies, in order to fundamentally enhance the intrinsic 
quality of the securities market, but also to fundamentally guide the healthy development of the securities market.

\section{Acknowledgements}

This paper is funded by the National Social Science Fund "based on mixed Copula Study on measurement and stability of systemic financial risks in China” (Project No.:18XTJ004).

\section{References}

[1] He Xiannan. Research on value investment in Chinese stock market [J]. Journal of Zhongnan University, 2004, (5): 117-122.

[2] Shao Xiaoyang, Su Jingqing, Yu Saint. Empirical study on book-market ratio effect of China Ashare market [J]. Management Science in China, 2004, 6 (12): 6-11.

[3] Xiao, Xu Xinzhong. An empirical study on the effectiveness of China's stock market value reversal investment strategy [J]. Economic Studies, 2004, (3): 55-64.

[4] Wang Jinbin. Value Premium China stock market---1994-2002 [J]. Financial Studies, 2004, (3): 79-89.

[5] Chen Yao, Zhou Xunnong. Behavioral finance Explanation of value investment strategy and its empirical research [J]. Systems Engineering, 2005, (7): 62-67.

[6] Chen Xiaohong, Wang Qi. Value investment strategy of small and medium-sized listed companies in China based on growth [J]. Systems Engineering, 2008, 1 (): 45-50.

[7] Song June, Chowa, Miu Yilin, Wu Charge. Research on value investment strategy based on the premium rate of A-H stock [J]. Journal of Systems Engineering, 2009, 5 (24): 574-580.

[8] Di Clemente A.C. and Romano C. Measuring portfolio value-at-risk by a Copula-EVT based approach [R]. University of Rome, 2003.

[9] Viviana Fernandez. Copula-based measures of dependence structure in assets returns [J]. Journal of Physica A, 2008, (387): 3615-3628.

[10] Karmakar, M, Paul, S. Intraday portfolio risk management using VaR and CVaR: A CGARCH-EVT-Copula approach [R]. International Journal of Forecasting, working paper, 2018.

[11] Karmakar, M. Dependence structure and portfolio risk in Indian foreign exchange market: A GARCH-EVT- Copula approach [J]. The Quarterly Review of Economics and Finance, 2017, 64: 275-291.

[12] Li Jun. Copula-EVT Based Tail Dependence Structure of Financial Markets in China [J]. Journal of southwest Jiaotong University, 2009, (1):66-72.

[13] Fu, Lin Lynn. Conditional VaR calculation based on extremum theory and Copula function [J]. Journal of Systems Engineering, 2009, 24 (5): 531-537.

[14] Li Yue Ray, Zhang Weiying, bear, Liang. Study on the control of stock index futures based on extreme value correlation analysis method [J]. Journal of Management Science, 2010, 13 (11): 104111.

[15] Liu Jiangfang, Zhang Zongyi. Research on stock correlation based on Copula real estate and financial industry [J]. Journal of Management Engineering, 2011, 1: 165-169.

[16] Zhou Xiaohua, Li Qiang, Zhang Pao. Risk measurement of China's diversified foreign exchange reserve currency portfolio based on COPULA-ASV-GPD [J]. Systems Engineering, 2012, 31 (1): 1-8.

[17] Zhou Xiaohua, Chen. Study on risk overflow measurement of small and gem based on copulaasv-evt-covar model [J]. Theory and practice of system engineering, 2016, 36 (3): 559-568.

[18] Li Qiang, Zhou Xiaohua, Li Yu. Risk measurement of QFII and HS300 index correlation based 
on Copula-ASV-EVT [J]. Theory and practice of system engineering, 2017, Panax Notoginseng (3): 570-579.

[19] Wu Xin, horse superb, Wang Shouyang. Parameter estimation of stochastic volatility model and empirical evidence of Chinese stock market [J]. Theory and practice of system Engineering, 2014, 34 (1): 35-44.

[20] Liu Zhidong. Portfolio Selection model based on Copula-GARCH-EVT and its genetic algorithm [J]. Application of theoretical methods of system engineering, 2006, 15 (2): 149-157.

[21] Battle Shelly, Zhang Shiying. Risk analysis of financial portfolio based on Copula-SV model [J]. Journal of Systems Management, 2007, 16 (3): 302-306.

[22] Li Pengju, Zhu Hui. Risk measurement of financial management products based on Copula function [J]. Theory and practice of system engineering, 2014, 34 (3): 663-667.

[23] Kim S, Shephard N. and Chib S. Stochastic volatility: Likelihood inference and comparison with ARCH models [J]. Review of Economic Studies,1998, (3): 361-393.

[24] McNeil AJ, Frey R. Estimation of tail-related risk measures for heteroscedastic financial time series: an extreme value approach [J]. Journal of Empirical Financial, 2000, (7): 271-300.

[25] Mcneil AJ, Frey R. Estimation of financial time series: an extreme value approach [R]. Working paper ETHZ.

[26] Patie P. Estimation of Value at Risk Using Extreme Value Theory [R]. http://www.math.ethz.ch/patie/VaR EVT. 2000.

[27] J.H. Shih, T.A. Louis, Inferences on the association parameter in copula models for bivariate survival data [J]. Biometrics. 1995, 51(4): 1384-1399.

[28] Longin. F, Solnik. B. Extreme correlation of international equity markets [J]. Journal of Finance, 2001, (56): 649-676.

[29] Ang. A, Chen J. Asymmetric correlations of equity portfolios [J]. Journal of Financial Economics, 2002, 63: 443-494.

[30] Ledford. A. W, Tawn. J. Concomitant tail behavior for extremes [J]. Adv. Appl. Prob., 1998, 30: 197-215.

[31] Joe H. Multivariate Models and Dependence Concepts [M]. London: Chapman \& Hall, 1997.

[32] Janet E, Heffernan. A Directory of Coefficients of Tail Dependence [M]. Extremes, 2000, 3(3): 279-290.

[33] A. Balbás, B. Balbás, R. Balbás. VaR as the CVaR sensitivity: Applications in risk optimization, J. Comput. Appl., 2017, 309: 175-185.

[34] Gildas M, Stephane G, Florence F. A class of multivariate copulas based on products of bivariate copulas [J]. Journal of Multivariate Analysis, 2015, 140: 363-376. 